

\section{Confiança: a base das marcas fortes}

\section{Trust: the basis of strong brands}

\section{Confianza: la base de las marcas fuertes}

\section{Rodolfo Araújo’}

$\mathrm{P}$ ense em uma empresa gigante, que atua em múltiplos setores altamente competitivos, como energia e telecomunicações, capaz de angariar centenas de bilhões de dólares por mês, além, dentre outros louros, ser eleita a companhia mais admirada dos Estados Unidos. E se essa organização se envolvesse em um escândalo financeiramente "comparável ao 11 de Setembro", de acordo com o economista Paul Krugman? Foi assim que a Enron se tornou um emblema nas reflexões sobre mundo corporativo e transparência no começo deste século, quando foi descoberta após passar anos, com a conivência de sua auditoria externa e de outros parceiros, maquiando balanços financeiros e, consequentemente, ocultando prejuízos bilionários a funcionários, investidores e demais partes interessadas.

O caso constituiu um divisor de águas bastante claro ao apontar que apenas uma reputação teoricamente sólida não era mais suficiente para sustentar os desafios presentes e futuros de uma empresa, sobretudo em um panorama de fluxos comunicacionais que começava a se habituar com blogs, redes sociais e outros canais responsáveis por uma dramática inversão nas tradicionais ordens midiáticas.

Mesmo quinze anos depois, o aviso ainda não foi totalmente absorvido pelo mercado. Recentemente, a indústria automobilística trouxe dois exemplos que traduzem a desconexão entre as práticas corporativas e 0 ambiente de transparência, complexidade, instantaneidade e horizontalidade que pauta esse campo.

0 mais vultoso é o da Volkswagen, que custou aos alemães mais de $€ 16$ bilhões em 2015, além de render à companhia uma depreciação instantânea de $23 \%$ em seu valor de mercado. Ao fraudar informações sobre dispositivos de emissões de gases, a fabricante envolveu-se em uma profunda depressão de confiança junto a governos, consumidores,

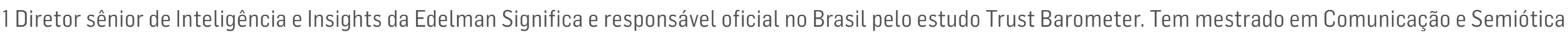

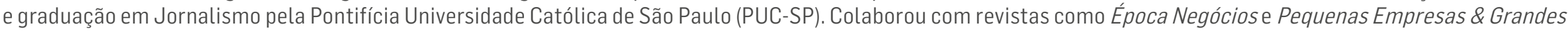

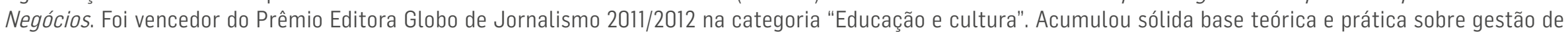

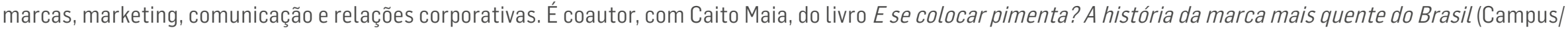
Elsevier, 2012), que explora o caso de estratégia da marca brasileira de varejo Chilli Beans. E-mail: rodolfo.araujo@edelmansignifica.com.
} 
investidores e funcionários, desfraldando uma série de consequências negativas, tais como a saída de líderes e a perda da liderança global na indústria de veículos.

Na mesma esteira, a montadora japonesa Mitsubishi admitiu publicamente ter falsificado testes de economia de combustível para tornar os índices de emissão mais favoráveis. Como resultado, o valor de suas ações chegou ao mínimo histórico e a perda imediata de valor somou US\$1,2 bilhão.

De forma análoga, no entanto, um estabelecimento bem menor, na rua Santa Ifigênia, em São Paulo, deu uma demonstração oposta. A loja e assistência técnica de eletrônicos Rei do iPhone aumentou suas vendas em $900 \%$ ao resolver - de graça - 0 problema de um cliente que tinha à mão um orçamento de R\$180,00 para consertar seu telefone. 0 pagamento? Divulgar 0 cartão da loja entre os amigos. Bastou que o consumidor satisfeito postasse nas redes sociais a história para o fato ganhar escala e, por si, angariar notoriedade. Claro: sem ajuda de nenhum plano de mídia.

Todos esses casos têm algo em comum e demonstram que tal questão não distingue setor, porte ou qualquer outra característica da marca em jogo. Fala-se, aqui, da relação entre reputação e confiança.

Reputação, em termos práticos, consiste em um julgamento no tempo presente a partir de ações desenroladas até 0 momento e desdobradas em uma série de percepções sedimentadas sobre um ator específico ou um grupo - como um governo, uma empresa, um movimento social, entre outros. É um olhar retrospectivo.

Enron, Volkswagen, Mitsubishi e Rei do iPhone sinalizam, evidentemente, que a dinâmica de comunicação e comportamento que servia ao mundo dos negócios no século XX não atende mais às expectativas contemporâneas da sociedade. Nesse sentido, cabe a todos os agentes envolvidos com a construção, proteção e promoção de marcas atentar para o futuro, ou seja, vislumbrar o que se espera das empresas, de seus produtos e serviços.

Com raiz latina vinculada à ideia de fé, confiança sintetiza, em diferentes dimensões, o eixo analítico para que se contemplem as demandas futuras em relação às corporações. Trata-se, primeiramente, de um sentimento que pauta relações, ou seja, trocas de aspectos comuns entre dois ou mais agentes de linguagem e comunicação. Atesta a saúde desta conexão e a predisposição de uma parte de esperar algo em relação ao interlocutor.

Pode-se falar de confiança, também, como indicador. Não à toa, vemos periodicamente avaliações quantitativas materializadas em índices que medem a confiança do consumidor.

Interessa, neste artigo, contemplar a confiança como um ativo intangível a ser gerenciado no âmbito das organizações. Quanto mais elevada, melhores condições tem uma empresa de fazer negócios e manter um alto padrão de competitividade. Dentro de suas paredes, ao desfrutar de um ambiente de intensa confiança, menos energia uma empresa gasta com processos e alinhamentos para, assim, ampliar seu potencial de rentabilidade. Poderá, também, reter e atrair mais talentos, reduzindo seu turnover e qualificando seu corpo de profissionais. Da mesma forma, fora de suas paredes, terá uma marca mais forte, com melhor acesso a crédito, novos mercados, imprensa, autoridades governamentais, consumidores, entre outros públicos.

Considerando que o tempo de construção de marcas é o real, cabe a uma empresa gerenciar, ininterruptamente, a qualidade das experiências por ela geradas junto à sua rede de audiências para, assim, converter em realidade as expectativas nutridas pelas pessoas em relação a suas atitudes e entregas. Quanto mais positiva a resultante desta equação, mais confiança e 
degraus acima essa organização galgará em termos reputacionais. Todavia, ao falhar quanto às demandas sociais, uma corporação perderá confiança e precisará investir muito mais para recuperar credibilidade dentro de um cenário pautado pela radicalização da transparência a partir de um panorama fundado na hiperconexão entre pessoas.

Com base nesse panorama, a Edelman, maior empresa de relações públicas do mundo, desenvolveu uma propriedade intelectual dedicada a analisar o nível de confiança de diferentes sociedades em relação a empresas, governos, organizações não-governamentais e mídia. Deste anseio nasceu o trust barometer (barômetro da confiança), um parâmetro aplicado globalmente por várias instituições para analisar as futuras expectativas da sociedade no que tange às respectivas atuações.

A décima sexta edição do estudo, divulgada em 2016, é fruto de 33 mil entrevistas realizadas em 28 países, entre os quais o Brasil se inclui.

De acordo com os resultados de nosso país, a confiança é referendada como um ativo diretamente ligado ao desempenho de negócios das empresas. Entre os respondentes brasileiros, 79\% mostram-se predispostos a comprar produtos e serviços de marcas em que confiam, enquanto $78 \%$ as recomendam a amigos e colegas e $57 \%$ chegam a pagar mais por aquilo que oferecem. Na direção contrária, empresas não confiáveis sofrem com a recusa dos consumidores (56\%), bem como as críticas (49\%) por parte deles junto aos pares. Em um ambiente reticular, confiança e desconfiança ganham proporções exponenciais.

Somos uma nação que demonstra confiar mais nas empresas (64\%) que no governo (21\%), sobretudo em função do cenário de extrema turbulência e questionamentos feitos acerca da atuação do poder público nos diferentes níveis federativos. Tal fato intensifica-se em virtude de o consumo ser a via mais imediata de exercício da cidadania junto a um grande contigente de pessoas que puderam ascender socialmente graças às políticas de assistência e inclusão solidificadas ao longo das últimas duas décadas. Por essa razão, espera-se muito mais das marcas, que se tornam obrigadas a transcender seus papéis e entregar à sociedade mais do que produtos e serviços de qualidade. A mídia, que passa por uma reordenação intensa e gradativa em virtude da comunicação digital e de rearranjos das cadeias de produção e circulação da informação, dispõe de $54 \%$ de confiança. Já as ONGs, que veem seus territórios em mescla crescente com os negócios sociais, detêm 62\% de credibilidade.

Com mais recursos financeiros, estruturais, humanos e um papel que toca necessidades materiais, simbólicas e afetivas dos indivíduos, as marcas veem diante de si um indicador favorável de expectativa, mas, ao mesmo tempo, defrontam 0 hercúleo desafio de cumprir o que delas se espera.

Alguns setores largam à frente de outros, como é o caso de tecnologia, costumeiramente líder das edições do estudo (83\%). Por vincular-se a atributos como progresso, inovação e qualidade de vida, destoa de serviços financeiros (56\%), por exemplo - uma indústria com mais dificuldades de legitimação. Não à toa, pode-se tomar como ilustração o alto grau de sofisticação com que os bancos trabalham a construção de suas marcas, com destaque para o Itaú, que soube pautar suas mensagens a partir do comportamento empresarial corretamente organizado em causas como educação, esporte, mobilidade urbana e cultura. Ao olhar para a sociedade além da oferta de produtos e serviços, o banco alinha-se aos indivíduos sob a perspectiva simbólico-afetiva e suas vendas deixam de ser um fim em si mesmo para se converterem em consequência de um bom julgamento feito pelas pessoas que se relacionam e veem autenticidade na marca.

Sim, o comportamento é o primeiro passo da comunicação de uma marca crível. No escopo metodológico do trust barometer, chegamos a uma matriz de atributos apreciados pelos respondentes que julgam as empresas a partir de cinco categorias: integridade, relacionaento, oferta e inovação, propósito e operações. Este prisma, a que chamamos de trust scorecard, os entrevistados julgam a performance das corporações em função dessas dimensões quanto à importância dada a elas versus a performance percebida em cada qual. 
Em 2009, após a reedição da grande depressão norte-americana e o debate ético deflagrado em torno da atuação empresarial, o grupo de atributos vinculados a operações perdeu importância junto às pessoas. Ou seja: porte, resultados gerados para os acionistas, visibilidade dos líderes e presença em grandes rankings deixaram de ser os principais quesitos a fundamentar a credibilidade de uma corporação. Pelo contrário: hoje, o julgamento de uma marca baseia-se em integridade, relacionamento e propósito, de onde se conclui que o comportamento empresarial comunica per se e as metas financeiras são consequência de uma conduta alinhada às expectativas dos públicos. Obviamente, sem um produto ou serviço inovador e de qualidade, nenhuma conversa tem início.

Temos, aqui, um panorama no qual as empresas se veem em permanente escrutínio em função da ética carregada em suas práticas, da responsabilidade demonstrada diante de crises, do nível de transparência de suas atividades, do trato junto aos colaboradores, da importância dada às opiniões dos clientes e da integração de causas socialmente relevantes ao dia a dia do negócio. A agenda de uma marca, com isso, amplia-se.

Para 90\% dos pesquisados, é possível, para as empresas, tomar atitudes que as façam auferir mais lucros e, ao mesmo tempo, contribuir para melhorar as condições econômicas e sociais nas comunidades onde atuam. Em 2015, 83\% concordavam com a assertiva. Intensifica-se, por essa razão, a ideia de sustentabilidade como pilar da confiança e a crença de que o comportamento comunica. Ainda mais no Brasil, em que as organizações privadas são vistas também como vetor central de desenvolvimento econômico, pois, ao cabo, são elas as indutoras de crescimento ao investirem, contratarem e tomarem as decisões finais de estímulo ao ambiente de negócios. Entre os que declararam ter confiado menos nas empresas em 2015, 40\% sustentaram tal resposta na falha, por parte das corporações, em endereçar o bem comum nos seus negócios. Ao mesmo tempo, 66\% dos que disseram confiar mais nas marcas atribuem tal voto ao protagonsimo empresarial no tocante ao crescimento econômico. 0 segundo critério mais valorizado foi "contribuir para o bem comum", apoiado por 50\% da amostra brasileira.

Entretanto, por onde tem início a paradigmática mudança comportamental nas empresas? É preciso avaliar, primeiro, quem são os agentes em que mais confiamos no momento de formar opinião sobre elas. Como é tradição no estudo, a "pessoa comum" mostra-se como o interlocutor mais crível nesse sentido para 82\%. Ou seja, o poder dos pares evidencia uma inversão na pirâmide de influência. 0 discurso institucional e detentores clássicos de poder veem-se diante da emergência e do empoderamento de pequenos agrupamentos e vozes individuais, distribuídos e articulados em rede, os quais dissolvem com mais facilidade as hierarquias tradicionais. Ao fim do dia, empresas se compõem de pessoas falando com pessoas, tendo como motivo um produto ou serviço. É um jogo de percepções, julgamentos e expectativas postos à prova em tempo real.

Entre os porta-vozes empresariais que registraram maior elevação da credibilidade em 2016 figuram os líderes: 14 pontos percentuais de ascensão para CEOs (66\%) e 11 pontos percentuais para membros da alta gestão (63\%). Agora, os indivíduos - uma vez empoderados - desejam saber quem são as pessoas que comandam as marcas e, no limite, são sinônimo de seus comportamentos e suas comunicações. Em um contexto de crise de representatividade, no qual os cidadãos parecem falar um idioma diferente das instituições, a responsabilidade final sobre a postura das entidades tende a desembocar cada vez mais na figura de seus líderes. A mesma lógica aplica-se aos criadores de conteúdo mais críveis em canais digitais, entre os quais as pessoas "comuns" lideram (84\%) e CEOs demonstram rápido crescimento em importância (67\%).

Os gestores e as gestoras de alto escalão deixam, portanto, de ser apenas responsáveis pelos resultados financeiros de curto prazo das marcas por eles comandadas. Para além dos trimestres, suas agendas expandem-se na direção do comportamento empresarial. Os respondentes esperam que CEOs falem sobre práticas de suas organizações e seu desempenho (45\%), mas também aguardam posicionamentos firmes sobre o quanto a empresa se prepara para o futuro (44\%), como também demandam análises sobre setores e o mercado em geral (37\%). Enquanto 81\% acreditam que os líderes corporativos devem falar de finanças, $85 \%$ creem que suas atuações devem contemplar pontos de vista sólidos sobre temas relevantes para a população, tais como desigualdade de renda, políticas públicas e causas socioambientais. Menos foco, mais visão periférica. 
Atualmente, porém, os respondentes veem nos CEOs um foco excessivo em resultados financeiros de curto prazo (68\%) e menos que o suficiente no impacto positivo de longo termo gerado por suas organizações (52\%). Empresas confiáveis são fruto de um processo iniciado junto aos líderes, porta-vozes primários de culturas corporativas orientadas ao impacto social, e de significado proveniente de suas atividades. Ao definirem o perfil dos líderes "ideais", os respondentes dizem julgá-los por seus valores pessoais (84\%) mais que pela formação acadêmica, considerada importante para $72 \%$. Cabe às lideranças personificar e ter alinhamento às marcas que encabeçam.

Afinal, todo processo de mudança é detonado a partir das fronteiras internas das organizações. Líderes inspiradores mobilizam colaboradores comprometidos, os quais tomam atitudes favoráveis às marcas para as quais trabalham. No Brasil, $77 \%$ dizem confiar nas empresas em que estão atualmente, enquanto a média global é 65\%. Trata-se de um excelente começo, pois funcionários que confiam nos empregadores têm, segundo o barômetro, maior predisposição para recomendar seus produtos e serviços (79\%), crer no futuro da organização (77\%), comprometer-se com a estratégia (82\%) e buscar fazer o melhor para os clientes (88\%). Se o desafio é gerar melhores experiências para os públicos com 0 objetivo de atender a suas crescentes expectativas, a lógica está definida. E, quanto mais atenta a organização for aos temas sociais, maior é o engajamento dos colaboradores.

Portanto, o estudo ilustra que a missão das marcas confiáveis no contexto contemporâneo se baseia na articulação de quatro dimensões essenciais:

1) Identidade: é necessário que a marca possua um sólido conjunto de crenças e valores que alimente sua cultura e seja seu ponto de sustentação em momentos de bonança e crise. É seu significado central, seu núcleo cultural e sua inspiração máxima, ponto de mobilização dos atores internos e externos.

2) Atitudes: conversão deste significado em práticas, as quais se materializam em processos, rituais, entregas, produtos, serviços, causas, conteúdos, comunicações, entre outros gestos capazes de tangibilizar a promessa gerada pela identidade.

3) Engajamento: a palavra-chave é diálogo. De acordo com o estudo, as pessoas formam opinião sobre uma empresa não apenas pelos meios tradicionais (televisão, rádio, revista etc.), mas também e em igual medida estratégica pelas mídias sociais e próprias, ou seja, os canais das próprias organizações. As pessoas desejam ter acesso a conteúdos gerados (e não apenas repercutidos) pelas marcas. Por isso, toda companhia - não importa o setor - é, também, uma corporação midiática. Isso leva as empresas a desenvolverem a capacidade de ter uma forte presença em todos os meios e não dependerem mais apenas de um grande investimento em visibilidade e mídia paga, os quais não contribuem integralmente para a criação de confiança.

4) Inteligência: para manter-se alinhada a seu tempo e fazer sentido junto às pessoas que com ela se relacionam, uma marca deve valer-se de dados e insumos permanentemente - do desenho da estratégia, passando pelo entendimento dos seus públicos, à mensuração dos resultados de suas ações de comunicação. Quanto mais afinada ao seu contexto, mais chances ela tem de se perenizar.

Depoimento recebido em 10.10.2016 e aceito em 18.10.2016. 